\title{
Presence of Silver Resistance Genes is not associated with Minimum Inhibitory Concentration of Silver Nanoparticles against Staphylococcus aureus and Escherichia coli
}

Original Article

Fahimeh Azadi

(MSc) Department of Microbiology,

School of Medicine, Golestan University of Medical Sciences,

Gorgan, Golestan, Iran

Naeme Javid

(PhD Candidate) Department of Microbiology, School of Medicine, Golestan University of Medical Sciences, Gorgan, Golestan, Iran

Hanieh Bagheri (iD

(MSc) Department of Microbiology, School of Medicine, Golestan University of Medical Sciences,

Gorgan, Golestan, Iran

Ezzat Allah Ghaemi

$(\mathrm{PhD})$ Department of Microbiology,

School of Medicine, Golestan

University of Medical Sciences,

Gorgan, Golestan, Iran and Laboratory

Science Research Center, Golestan

University of Medical Sciences,

Gorgan, Golestan, Iran

Corresponding author: Ezzat Allah Ghaemi

Email: eghaemi@yahoo.com

Tel: +989113711770

Address: Department of Microbiology, School of Medicine, Golestan University of Medical Sciences, Gorgan, Golestan, Iran

Received: 2019/10/23

Revised: 2019/12/11

Accepted: 2019/12/17

\section{cc) (i) (8)}

This work is licensed under a Creative Commons Attribution 4.0 License.

DOI: $\underline{10.29252 / \mathrm{mlj} .14 .4 .7}$

\section{ABSTRACT}

Background and objectives: Drug resistance in Staphylococcus aureus and Escherichia coli, as severe pathogenic bacteria, has become a health challenge. However, nanoparticles have been introduced as effective candidates for their eradication. In this study, we investigated presence of genes involved in conferring resistance to silver nanoparticles in $S$. aureus and E. coli isolates and evaluated its association with minimal inhibitory concentration (MIC) of the nanoparticles against these isolates.

Methods: The MIC of silver nanoparticles against 121 clinical isolates of $E$. coli and $183 \mathrm{~S}$. aureus isolates was assessed by broth microdilution assay. Presence and expression of the silver resistance genes $($ silE, silR/S) in the isolates were investigated by PCR and real-time PCR, respectively.

Results: The silE gene was found in three (1.6\%) S. aureus and four $(3 \%) \mathrm{E}$. coli isolates. MIC of silver nanoparticles against $S$. aureus isolates with the silE gene was 1,2 and 8 $\mu \mathrm{g} / \mathrm{ml}$. Moreover, the MIC of the nanoparticles against silEpositive E. coli isolates was $16 \mu \mathrm{g} / \mathrm{ml}$ in three cases and $8 \mu \mathrm{g} / \mathrm{ml}$ in one case. None of the $S$. aureus isolates contained the $s i l R / S$ gene, but presence of both silE and silR/S was confirmed in two E. coli isolates. Real-time PCR showed no sil expression in the isolates containing the resistance genes.

Conclusion: The frequency of the silver resistance genes among $S$. aureus and E. coli isolates is very low. There is no relationship between presence of the resistance genes and the MIC value of silver nanoparticles.

Keywords: Staphylococcus aureus, Escherichia coli, Silver particles, MIC 


\section{INTRODUCTION}

Due to the increased prevalence of multi-drug resistant pathogens that do not respond to conventional antibiotics $(1,2)$, pharmaceutical companies and scientists are seeking alternative antimicrobial agents against these pathogens. Among various types of nanomaterials, silver particles have been proven to have higher antimicrobial activity against bacteria and viruses (3). Although silver has been used for treatment of illnesses such as neonatal gonococcal conjunctivitis and burn wound infections (4), its utilization declined gradually after the emergence of antibiotics. However, the use of metal ions, such as silver, for the treatment of infections has been recently reconsidered due to bacterial resistance and side effects of chemical drugs (5).

Resistance to silver is very limited (6) with unclear mechanisms and a possible plasmid origin. Plasmid pMG101 (180 kb) (6-9) was first identified by McHugh et al. in Salmonella typhimurium isolates (10). However, the plasmid has been also detected in Enterobacter, Escherichia coli, Pseudomonas, Acinetobacter, Klebsiella and Staphylococcus aureus (6). According to Wood et al., silverresistance conferring genes of non-pathogenic Enterobacter cloacae isolates are located on this plasmid (11). The plasmid also encodes genetic information on resistance to other compounds such as mercury, tellurite and several antibiotics including ampicillin, chloramphenicol, tetracycline, streptomycin and sulfonamides (6-9). A region of PMG101 that increases resistance to silver has been cloned and sequenced (GenBank accession AF067954) (9). The silver-resistance gene cluster consists of nine genes (6-9), the most important of which is silE that encodes the silver-binding periplasmic protein (9). The protein pumps silver nanoparticles out of the cytoplasm through activation of diffusion pumps and prevents access of these particles to crucial cell components, ultimately inducing silver resistance (8). Upstream of the silE gene, the silR (transcriptional responder) and silS (membrane sensor kinase) genes seem to be involved in signal transduction and regulation of silver resistance (9).

Three possible mechanisms of silver nanoparticles toxicity are: a) uptake of free silver nanoparticles followed by disruption of ATP production and DNA replication, $b$ ) reactive oxygen species generation by silver nanoparticles, and c) direct damage to the cell membrane by silver nanoparticles (10). Considering the recent increased interest in synthesis of metallic nanoparticles for controlling microbial infections, and the growing concern about silver resistance, we aimed to evaluate the frequency and expression of the silver resistance genes and their impact on antimicrobial activity of silver nanoparticles against $S$. aureus and E. coli, as common nosocomial pathogens.

\section{MATERIALS AND METHODS}

Colloidal silver nanoparticles (size: $26 \mathrm{~nm}$ ) were purchased from Pars Nano Nasb Co. (Iran). A serial dilution of nanoparticles was prepared according to our previous study (12). The study were carried out on 183 confirmed $S$. aureus isolates from nasal cavity of healthy carriers (12 isolates), patients (96 isolates) and food samples (75 isolates) (13), and 121 confirmed clinical isolates of E. coli from the microbial collection of Golestan University of Medical Sciences (Iran) during 2009-2014. Fresh and overnight culture of pure organisms was used for bacterial suspension preparation according to reference methods for determining minimal inhibitory concentration (MIC) of silver nanoparticle and DNA extraction.

The MIC of silver nanoparticle against $S$. aureus and E. coli isolates was obtained in our previous study (12). In addition, association of MIC with presence of the sil genes was assessed.

DNA of isolates was extracted using a phenol/chloroform/isoamyl alcohol mixture (14). Concentration and purity of the extracted DNA $(n g / \mu \mathrm{L})$ was determined based on the A260/A280 ratio. Amplification of the resistance genes was done using a commercial kit (GenetBio Co., South Korea) and specific primers (11) (Table 1).

Polymerase chain reaction (PCR) reaction solution $(50 \mu \mathrm{l})$ contained $5 \mu \mathrm{l}$ buffer $(10 \mathrm{x}), 3$ $\mu 1 \mathrm{MgCl}_{2}(50 \mathrm{mM}), 1 \mu \mathrm{dNTP}(10 \mathrm{mM}), 1 \mu \mathrm{l}$ of each primer (10 pmol), $0.4 \mu \mathrm{l}$ Taq DNA polymerase (5 units), 33.6 $\mu \mathrm{l}$ nuclease-free water and $5 \mu \mathrm{l}$ sample.

The PCR reaction was carried out in a PeQLab thermocycler under the following conditions: Initial denaturation at $95{ }^{\circ} \mathrm{C}$ for 3 minutes, secondary denaturation at $95^{\circ} \mathrm{C}$ for 40 seconds, 
annealing at $56{ }^{\circ} \mathrm{C}$ for 40 seconds, extension at $72{ }^{\circ} \mathrm{C}$ for 40 seconds, and 45 cycles of final extension at $72{ }^{\circ} \mathrm{C}$ for 10 minutes. PCR products were electrophoresed on $1.5 \%$ agarose gel. The PCR products were sent to Macrogen Co. (South Korea) for Sanger sequencing. The results were evaluated for similarity with known sequences of the sil gene using BLAST (available at www.ncbi.nlm.nih.gov).

RNA was extracted from overnight culture of pure microorganisms using the RNX-Plus solution (Sinagen Co. Iran, Lot No: 11667157001). Next, cDNA was synthesized using RevertAid First Strand cDNA Synthesis kit (Thermo Scientific Co. Germany, REF: K1622). The real-time PCR experiment was performed using the same primers used previously.

The real-time PCR master-mix (Thermo Scientific Co. Germany, Lot No.: 1605523) consisted $12.5 \mu \mathrm{l}$ of mastermix, $0.5 \mu \mathrm{l}$ of each primer $(10$ pmol $), 2 \mu \mathrm{l}$ cDNA and $10 \mu \mathrm{l}$ nuclease-free water in a final volume of $25 \mu \mathrm{l}$. The reaction was carried out in the ABI Prism 7300 real-time thermocycler (Applied Biosystems Co.) under the following conditions: initial denaturation at $95{ }^{\circ} \mathrm{C}$ for 10 minutes, and 40 cycles of denaturation at 95 ${ }^{\circ} \mathrm{C}$ for 15 seconds, annealing at $60{ }^{\circ} \mathrm{C}$ for 40 seconds, and extension at $72{ }^{\circ} \mathrm{C}$ for 40 seconds. An E. coli isolate containing the sil gene with $98 \%$ similarity to that of standard plasmid pEC5207 was used as the positive control.

Table1. Sequence of primers used in the study (11)

\begin{tabular}{ccc}
\hline Gene & Primer (5' to 3') & Amplicon size \\
\hline sile & F: AGGGGAAACGGTCTGACTTC & $220 \mathrm{bp}$ \\
Sil $\boldsymbol{R} / \boldsymbol{S}$ & R:ATATCCATGAGCGGGTCAAC & $189 \mathrm{bp}$ \\
& F:GGCAATCGCAATCAGATTTT & \\
\hline
\end{tabular}

\section{RESULTS}

Of $183 \mathrm{~S}$. aureus isolates, only three isolates $(1.6 \%)$ had the silE gene. Two of these isolates were methicillin-sensitive $S$. aureus and one isolate was methicillin-resistant $S$. aureus (MRSA). All positive cases were isolated from patients, and none of the isolates from healthy carriers and food samples contained the silE gene (Figure 1).

The MIC of silver nanoparticles against $S$. aureus isolates was 1,2 and $8 \mu \mathrm{g} / \mathrm{ml}$. None of the $S$. aureus isolates was positive for the silR/S genes.

Of $121 \mathrm{E}$. coli isolates, four isolates (3\%) contained the silE gene (Figure 2).

The MIC of silver nanoparticles was $16 \mu \mathrm{g} / \mathrm{ml}$ against three isolates and $8 \mu \mathrm{g} / \mathrm{ml}$ against the remaining isolates. The simultaneous presence of silE and silR/S genes was confirmed only in two isolates (1\%) (Figure 3). Similarity of the silE gene between $S$. aureus and $E$. coli isolates was $94-98 \%$. In addition, the silE gene had $94-100 \%$ similarity with the pEC5207 plasmid. The genes were submitted into GenBank database with the following GenBank accession numbers: MG816306, MG816307, MG816308, MG816309, MG816310, MG816311 and MG816312. According to the results of the real-time PCR experiment, the expression level of silE and silR/S genes was undetectable in the isolates containing the resistance genes. 
Figure 1. Gel electrophresis of PCR products for presence of silE gene in $S$. aureus isolates. M: Molecular weight (1000 bp, Fermentas Co.), 1: positive control, 2: negative control, 3-5: $S$. aureus isolates containing the silE gene.

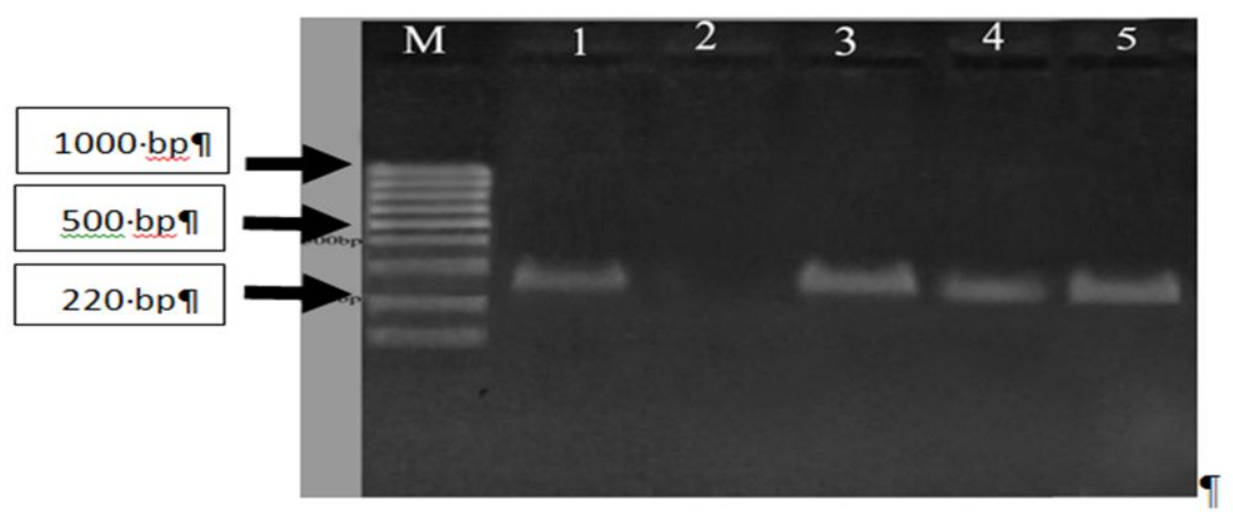

Figure 2. Gel electrophoresis of PCR products for presence of $s i l E$ gene in $E$. coli isolates. M: Molecular weight (1000 bp, Fermentas Co.), 1: positive control, 2: negative control, 3-6: E. coli isolates containing the silE gene.

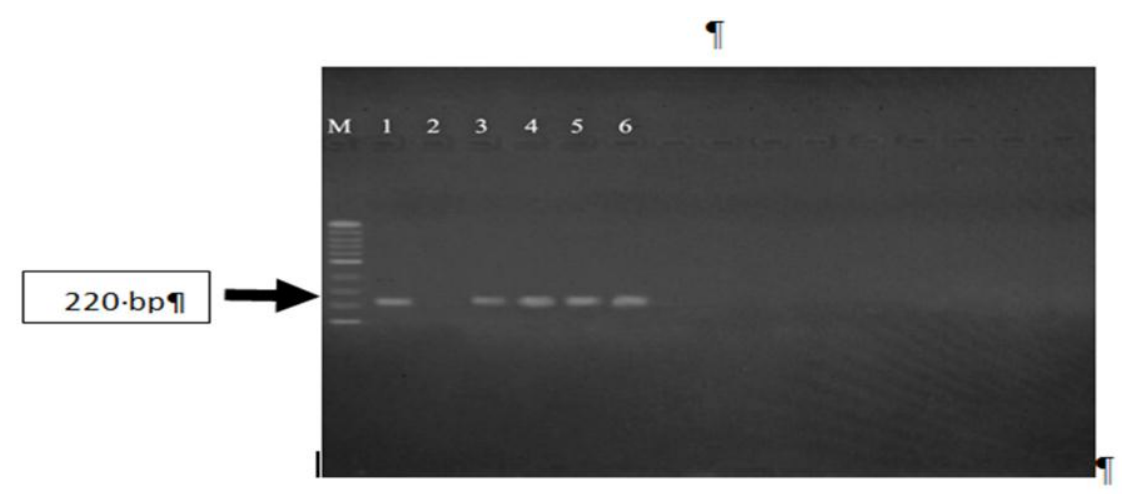

Figure 3. Gel electrohpresis of PCR products for presence of silR/S gene in $E$. coli isolates. M: Molecular weight (1000 bp, Fermentas Co.), 1: positive control, 2: negative control, 3 and 4: E.coli isolates containing the silR/S gene.

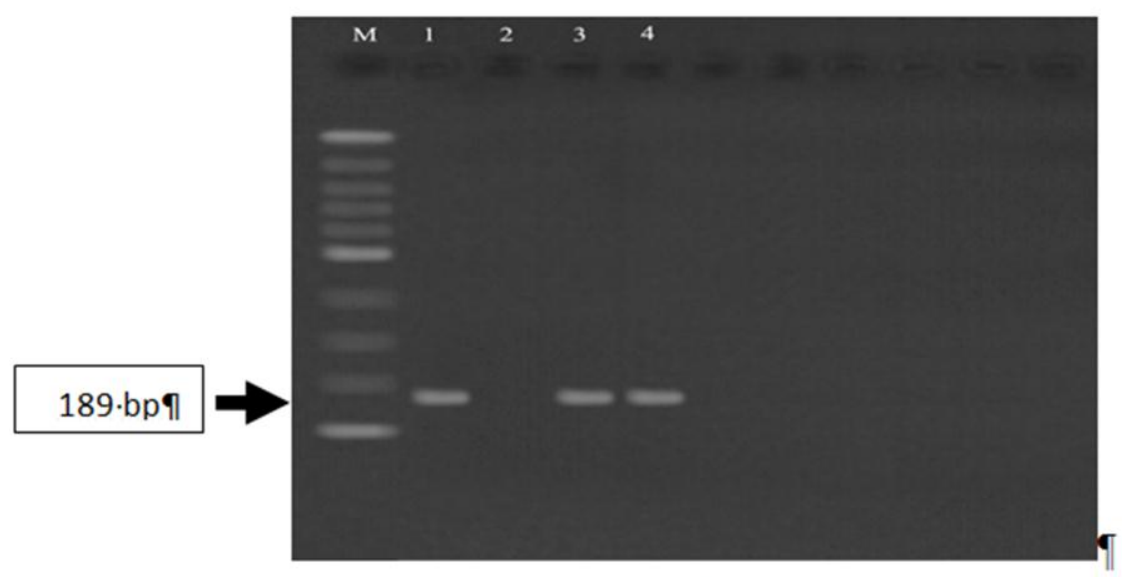




\section{DISCUSSION}

We investigated the frequency and expression of silver resistance genes and their association with MIC of silver nanoparticles. In this study, three $S$. aureus isolates $(1.6 \%)$ contained the silE gene, while none of the isolates contained the silR and sils genes. In most previous studies, the frequency of the silE gene in $S$. aureus isolates did not exceed $6 \%$. In studies of Hosseini et al. (15) and Sütterlin (16), none of the $S$. aureus isolates contained the sil gene. In study of Loh et al. (17), 6\% of the MRSA isolates contained the silE gene, which is in line with our findings.

In our study, the frequency of the silE gene was $3 \%$ among $E$. coli isolates. However, only $1 \%$ of the isolates contained the silE and silR/S genes simultaneously. In study of Woods et al. (11) in England, six bacteria (two from humans, four from horses) contained the genes, all of which were identified as $E$. cloacae. However, in the study of Sütterlin (16) on 216 E. coli isolates, the silE gene was found in 13 human clinical isolates (6\%), 10 of which also contained the silR and silS genes.

In a study by Sutterlin et al. (18), the prevalence of silE, silP and sils genes in intestinal Enterobacter and Klebsiella isolates was higher than that in other bacteria. The prevalence of these genes was $48 \%$ and $41 \%$ in Enterobacter and Klebsiella isolates, respectively. However, the abundance of these genes in E. coli was around $4 \%$.

Based on the results, all isolates with the silver resistance genes were of human origin. The MIC of silver nanoparticles against $E$. coli isolates positive for the resistance genes was more than $S$. aureus isolates positive for the resistance genes. Moreover, the MIC of E. coli isolates containing the silE, silR and silS genes was identical to that of isolates that only

\section{REFERENCES}

1. Franci G, Falanga A, Galdiero S, Palomba L, Rai M, Morelli G, Galdiero M. Silver nanoparticles as potential antibacterial agents. Molecules. 2015; 20(5): 8856-74.

2. Namasivayam SKR, Preethi M, Bharani ARS, Robin G, Latha B. Biofilm inhibitory effect of silver nanoparticles coated catheter against Staphylococcus aureus and evaluation of its synergistic effects with antibiotics. Int J Biol Pharm Res. 2012; 3(2):259-65.

3. Rai M, Yadav A, Gade A. Silver nanoparticles as a new generation of antimicrobials. Biotechnology advances. $2009 ; \quad 27(1)$ : 76-83. https://doi.org/10.1016/j.biotechadv.2008.09.002. contained the sile gene and strains without sil genes. This indicates that the MIC of silver nanoparticles is not associated with presence of the resistance genes but may be related to their expression level. This finding is in line with results of Sutterlin et al. (18).According to Silver (9) and Sütterlin (16), the silE and $\mathrm{SilR} / \mathrm{S}$ genes on operon sil are the main cause of resistance. Therefore, we evaluated the presence of these genes. Similar to our study, Sutterlin et al. (18) assessed the frequency of three silver operon genes. Given the fact that the silR/S genes regulate the operon, the absence of the genes or their unexpression in $S$. aureus and $E$. coli can be indicative of operon repression thus cannot cause resistance to the silver nanoparticles.

It should be mentioned that the present study did not cover all genes involved in silver nanoparticle resistance. In addition, the relationship between the MIC of silver nanoparticles and sil operon needs to be evaluated.

\section{CONCLUSION}

The frequency of the silver resistance genes among $S$. aureus and $E$. coli isolates is very low. There is no relationship between presence of the resistance genes and the MIC value of silver nanoparticles.

\section{ACKNOWLEDGMENTS}

This work was financially supported by the Laboratory Science Research Center, Golestan University of Medical Sciences, Iran as a part of an MSc thesis. We are grateful to the Laboratory Science Research Center and Deputy of Research and Technology of Golestan University of Medical Sciences for supporting this study.

\section{CONFLICT OF INTEREST}

The authors declare that there is no conflict of interest regarding publication of this article.

4. Lara HH, Garza-TreviñoEN, Ixtepan-Turrent L, Singh DK. Silver nanoparticles are broad-spectrum bactericidal and virucidal compounds. Journal of nanobiotechnology. $2011 ; \quad 9(1): \quad 30$. https://doi.org/10.1186/1477-3155-9-30.

5. Lara HH, Garza-TreviñoEN, Ixtepan-Turrent L, Singh DK. Synergistic effects between silver nanoparticles and antibiotics and the mechanisms involved. Journal of medical microbiology. 2012; 61(12): 171926. doi: 10.1099/jmm.0.047100-0.

6. Finley P, Peterson A, Huckfeldt R. The prevalence of phenotypic silver resistance in clinical isolates. Wounds: a compendium of clinical research and practice. 2013; 25(4): 84-8. 
7. Chopra I. The increasing use of silver-based products as antimicrobial agents: a useful development or a cause for concern?. Journal of antimicrobial chemotherapy. 2007; 59(4): 587-90. https://doi.org/10.1093/jac/dkm006.

8. Percival SL, Bowler P, Russell D. Bacterial resistance to silver in wound care. Journal of hospital infection. 2005; 60(1):

1-7. https://doi.org/10.1016/j.jhin.2004.11.014.

9. Silver S. Bacterial silver resistance: molecular biology and uses and misuses of silver compounds. FEMS microbiology reviews. 2003; 27(2-3): 341-53. https://doi.org/10.1016/S0168-6445(03)00047-0.

10. Durán N , Durán M , Bispo de Jesus M, Seabra A , Fávaro W, Nakazato G. Silver nanoparticles: a new view on mechanistic aspects on antimicrobial activity. Nanomedicine: Nanotechnology, Biology and Medicine. 2016; 12(3): 789-99. https://doi.org/10.1016/j.nano.2015.11.016.

11. Woods E, Cochrane C, Percival S. Prevalence of silver resistance genes in bacteria isolated from human and horse wounds. Vet microbial. 2009; 138(3-4): 325-9. https://doi.org/10.1016/j.vetmic.2009.03.023.

12. Azadi F, Jamali A, Baei B , Bazouri M, Shakeri F, Ghaemi EA. Minimum inhibitory concentration of silver nanoparticle against Staphylococcus aureus and its relation with Methicillin resistance and bacterial source of isolation. J Gorgan Univ Med Sci. 2016; 18(3): 86-91.
13. Taherirad A, Jahanbakhsh R, Shakeri F, Anvary S, Ghaemi EA. Staphylococcal cassette chromosome mec types among methicillin-resistant Staphylococcus aureus in northern Iran. Jundishapur J Microbiol. 2016; 9(8): e33933.

14. Shakeri F, Shojai A, Golalipour M, RahimiAlang S, Vaez H, Ghaemi EA. Spa Diversity among MRSA and MSSA Strains of Staphylococcus aureus in North of Iran. International journal of microbiology. 2010; Article ID 351397. doi:10.1155/2010/351397.

15. Hosseini F, Mirzaii M, Salehi M. The Study of CrossResistance Between Silver and Antibiotics in Isolated Bacterial Strains From A Burns Unit. Advances in Environmental Biology. 2011; 5(10): 3164-3172.

16. Sütterlin S. Aspects of bacterial resistance to silver: ActaUniversitatisUpsaliensis. 2015.

17. Loh JV, Percival SL, Woods EJ, Williams NJ, Cochrane CA. Silver resistance in MRSA isolated from wound and nasal sources in humans and animals. Int $\begin{array}{llll}\text { Wound } & \text { J. } & \text { 2009; } & 6(1):\end{array}$ https://doi.org/10.1111/j.1742-481X.2008.00563.x.

18.Sutterlin S, Dahlo M, Tellgren-Roth C, Schaal W, Melhus A. High frequency of silver resistance genes in invasive isolates of Enterobacter and Klebsiella species. J Hosp Infect. 2017; 96(3): 256-61. https://doi.org/10.1016/j.jhin.2017.04.017

\section{How to Cite:}

Azadi F,. Javid N,. Bagheri H,. Ghaemi EA. [Presence of Silver Resistance Genes is not associated with Minimum Inhibitory Concentration of Silver Nanoparticles against Staphylococcus aureus and Escherichia coli]. mljgoums. 2020; 14(4): 7-12. DOI: 10.29252/mlj.14.4.7 